Revista de la red interuniversitaria de estudios sobre las literaturas rioplatenses contemporáneas en Francia

$22 \mid 2021$

¿Cómo se cuenta una vida? El retorno de lo biográfico en la literatura rioplatense contemporánea

\title{
De espectáculos y absolutos. Formas de la vida en Guebel y Becerra
}

De spectacles et d'absolus. Formes de vie chez Guebel et Becerra

On spectacles and absolutes. Forms of Life in Guebel and Becerra

\section{Julio Premat}

\section{OpenEdition}

Journals

Edición electrónica

URL: http://journals.openedition.org/lirico/9964

DOI: $10.4000 /$ lirico.9964

ISSN: 2262-8339

Editor

Réseau interuniversitaire d'étude des littératures contemporaines du Río de la Plata

Referencia electrónica

Julio Premat, «De espectáculos y absolutos. Formas de la vida en Guebel y Becerra», Cuadernos LIRICO [En línea], 22 | 2021, Publicado el 11 marzo 2021, consultado el 16 marzo 2021. URL: http:// journals.openedition.org/lirico/9964 ; DOl: https://doi.org/10.4000/lirico.9964

Este documento fue generado automáticamente el 16 marzo 2021.

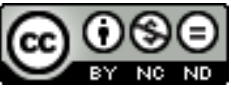

Cuadernos LIRICO está distribuido bajo una Licencia Creative Commons Atribución-NoComercialSinDerivar 4.0 Internacional. 


\title{
De espectáculos y absolutos. Formas de la vida en Guebel y Becerra
}

\author{
De spectacles et d'absolus. Formes de vie chez Guebel et Becerra \\ On spectacles and absolutes. Forms of Life in Guebel and Becerra
}

\author{
Julio Premat
}

\section{Dos novelas, dos tradiciones}

1 Para contestar la pregunta que abre este número de Cuadernos LIRICO sobre las estrategias formales de las narraciones de una vida, dos novelas. Dos novelas recientes de escritores argentinos conocidos, dos novelas ambiciosas: El espectáculo del tiempo de Juan José Becerra (2015) y El absoluto de Daniel Guebel (2016). Dos novelas extensas que recuperan una serie apretada de tradiciones. Ambas están estructuradas a partir de dos maneras, dispares y hasta opuestas, de "contar una vida", pero ambas coinciden en exacerbar dispositivos, desplazar tradiciones, actualizar interrogantes $\mathrm{y}$, ante todo, proponer configuraciones insólitas. Permiten, pienso, volver visible algunos aspectos de las formas y los alcances que reviste lo biográfico en la actualidad.

El absoluto es una extraña mezcla de una erudición especulativa de corte borgeano, una especie de historia literaria alternativa que expone, profusamente, diégesis, intrigas, personajes, en una dinámica de desvío, diversión y pérdida programática del rumbo, ya señalada como característica del autor (Oliver, Conte, Pauls en Adriaensen y Maier 2015). El motor de los relatos es una novela familiar, en el sentido freudiano de fabulación de orígenes alternativos y exaltantes, que inventa en este caso un linaje masculino excepcional, un linaje de creadores que, significativamente, no le llega al hijo varón por vía paterna sino materna (la madre es la narradora de la vida de su padre, tío, abuelo, bisabuelo y tatarabuelo). Leemos entonces un recorrido por la vida de cinco "genios", creadores melancólicos que arranca a fines del siglo XVIII ruso y que culmina en una primera persona en Argentina. Solo uno, Alexander Scriabin, es un personaje histórico y algunos aspectos de la biografía del músico modelizan el conjunto; los otros se apellidan "Deliuskin", retomando el nombre de un compositor inglés, 
contemporáneo de Scriabin, Frederick Delius. El punto de llegada es la vida de un niño, que en la sexta y última parte ("Yo"), se incluye en la continuación de esos genios, todo lo cual remite a las habituales representaciones de infancia de escritores y a una especie de autoficción. El conjunto está dominado por una mirada megalomaníaca pero irónica: los antepasados de los que se trata participaron, sin ser reconocidos, en grandes transformaciones culturales y sociales de la Humanidad, e intentaron recurrentemente acceder a un "absoluto" gracias a varios tipos de creación. El niño, el último representante de la serie, también se acerca a ello con la invención de una máquina del tiempo. Pero la historia es la de un fracaso: al "absoluto" del título, anhelado, se lo roza sin poder asirlo.

3 El espectáculo del tiempo es un vaivén aleatorio entre ciento veinticinco secuencias narrativas encabezadas por una fecha escueta (un año), secuencias que, en su mayoría, remiten a diferentes momentos de la vida de Juan Guerra, el narrador protagonista, y de la vida de su padre, a lo largo de más de cincuenta años. El conjunto se presenta como una mezcla de diario y de reconstrucción memorial, ambos traspapelados. En esa profusión de relatos el personaje del padre ocupa un lugar casi protagónico aunque negativo: es un padre frustrado, fracasado, intrusivo $-\mathrm{y}$ opuesto por lo tanto a los genios en Guebel-. La novela no postula la inteligibilidad de ninguna vida, ni la propia, ni la del padre, limitándose a poner constantemente sobre el tapete la cuestión de la subjetividad confrontada a la experiencia. Por otro lado, el conjunto desdeña cualquier tipo de totalidad, ya que en ningún momento se cimienta una historia ni un relato coherente; se trata más bien de una acumulación de momentos, muchas veces marcados por lo visual-descriptivo, que están dispuestos como un panóptico agujereado, como una simultaneidad absurda de momentos distintos o, lo dice el título, como un espectáculo, un espectáculo del tiempo en el que, radicalmente, no subyace ningún sentido ni ninguna identidad para el sujeto - lo que Becerra, por otro lado, reivindica programáticamente (2019) - . A ojos vista, el dispositivo propuesto conlleva, no una hipótesis, pero sí una praxis sobre lo que es una vida y cuáles son las dificultades para pasar de una mostración (el espectáculo) a una narración coherente y explicativa, en particular por lo improbable de cualquier cronología lineal. En un artículo célebre, Pierre Bourdieu (1995) desmonta lo que llama la "ilusión biográfica", es decir la creencia de que la vida es un todo coherente, orientado y ordenado según un modelo cronológico que equivale a un modelo lógico (84): la vida representada por Becerra está en los antípodas de esos tópicos.

4 Ahora bien, si las dos novelas permiten responder a la pregunta del "cómo se cuenta una vida" es, ante todo, porque ambas recuperan modelos identificables en la historia literaria. Dos tradiciones son perceptibles en la presentación esbozada, tradiciones fundamentales en la literatura del pasado y que remiten a su vez a tendencias que se prolongan o resurgen con fuerza en la literatura contemporánea. La primera forma, la primera tradición, es la expansión de la escritura del yo o de la intimidad, bajo el signo doble de la rememoración por un lado y de la transmisión directa de experiencias por el otro: diarios, crónicas, memorias, autobiografías que, desde el lejano propósito de contarse a sí mismo de Rousseau en sus Confesiones, no ha dejado de transformarse en la literatura moderna hasta volverse, hoy, una forma dominante, bajo las variantes de la literatura memorialista por un lado y de la autoficción intimista por el otro. En el marco argentino, el fenómeno ha sido denominado "giro subjetivo" (Sarlo 2007: 17-22) 
y "giro autobiográfico" (Giordano 2008), pero supera con creces las fronteras nacionales.

5 La segunda tradición es la biografía, una forma narrativa con un noble linaje que ya está presente en las Vidas paralelas de Plutarco, pasa por la hagiografía y da lugar a un género aparte, muy vigente todavía hoy y también presente en la literatura argentina (Avaro, Musitano y Podlubne 2018), pero que se desvió, a fines del siglo XIX, hacia una modalidad específica de ficciones biográficas, las vidas imaginarias de Marcel Schwob. Esa especie de subgénero híbrido entre historia y ficción, esa "bioficción" (Gefen 2012), es un tipo de relato en plena expansión en Francia desde hace treinta años (en particular después de la publicación de las Vidas minúsculas de Pierre Michon), un relato que se ha despojado de cualquier prurito de relación con la verdad, los documentos, lo referencial, la sinceridad, acentuando una tendencia general de las biografías (Mazzucchelli en Avaro, Musitano y Podlubne 2018). Un subgénero que, gracias a su recuperación por Alfonso Reyes pero sobre todo por Jorge Luis Borges, desarrolló su propia tradición en América Latina, en la cual un libro de referencia es La literatura nazi en América de Roberto Bolaño, pero que tiene muchísimos avatares anteriores y posteriores, que ya han sido señalados en tanto linaje específico (Premat 2010, Crusat 2015) y que Lorena Amaro llama "fábulas biográficas" (2017 Web).

6 Sin lugar a dudas, la presencia, visible, de estas tradiciones en Guebel y en Becerra, es digna de ser comentada, también en tanto que síntoma de la situación contemporánea: las maneras en las que estos autores leen el corpus heredado y recuperan formas nos dan indicios sobre el momento de la historia de la novela en el que ambos se inscriben. Las dos variantes citadas, en diálogo lateral con la historia una, con la autobiografía la otra, son sintomáticas de un fenómeno que excede esa interacción con los referentes genéricos y llevan a una evaluación más amplia del fenómeno, es decir una evaluación de la presencia, la validez y los alcances de lo biográfico.

7 En ese sentido, digamos que el relato de la vida, en tanto que molde lógico, además de cristalizarse en algún dispositivo formal reconocible (un género o subgénero), puede considerarse como un esquema narrativo siempre vigente en Occidente (nacimiento/ desarrollo/muerte de un individuo en complemento o contrapunto con el itinerario Génesis/Apocalipsis o partida/regreso). Alrededor de él se dirimieron y dramatizaron una serie de cuestiones que siguen siendo, hoy, las que atraviesan la literatura. Y, más precisamente, la expansión de lo biográfico tendría que ver con la situación de la novela contemporánea: la vida sería la última historia narrable, en un período de debilitamiento de lo novelesco. Más allá de su relación con la historia (relato veraz y documentado de lo sucedido) y de la crónica (aprehensión veloz, día a día, de lo vivido), el relato de una existencia implica a veces (es el caso en las dos novelas mencionadas) una dimensión utópica, en los antípodas de un realismo de lo inmediato, directamente expresivo de lo social, un realismo repetitivo y previsible, como el que leemos en un momento de proliferación de storytellings biográficos generalizados, tanto en los reincidentes biotopics o en una chata literatura confesional.

\section{Del contexto al anacronismo}

8 Sin embargo, explicar estas dos novelas por una relación directa con el período de publicación sería engañoso: las novelas parten de ese contexto, se enmarcan en él o dialogan con él, pero de manera conflictiva, con una programática voz altisonante, en 
desacuerdo, a destiempo. En muchos aspectos, El absoluto y El espectáculo del tiempo son novelas anacrónicas, en la medida en que retoman formatos e ideales de una novela del pasado, en este caso los de una supuesta "novela total", como las grandes novelas de los sesenta en América Latina.

No sé si la categoría de "novela total" es operativa, pero cierto es que El espectáculo del tiempo y El absoluto se inscriben en un fenómeno tan marginal como constante, y es el de autores o autoras que, según las circunstancias de su carrera, apuestan a un cambio de dimensión, de ambición, de lo que escriben, sea para afirmar una identidad artística naciente, sea para intentar ocupar un lugar de mayor reconocimiento después de años de escritura, sea inclusive para cerrar, con una obra de mayor trascendencia, una vida de creación (y entonces la "gran" novela es póstuma). Evidentemente, Becerra y Guebel se inscriben en ese gesto programático, que es el de la ambición de pasar a una "gran" novela y la de crear, con ella, un acontecimiento. Al hacerlo, ponen en escena una percepción conflictiva del tiempo, ya que la apuesta de la extensión textual, según el modelo canónico de "novela total", la de Proust, que implicaba un alargar la novela que iba de par con alargar la vida. Otros ejemplos del fenómeno en los últimos treinta años de literatura rioplatense: Osvaldo Lamborghini Tadeys (1983/1994), Alberto Laiseca, Los Sorias (1998), Martín Caparrós, La historia (1999), Alan Pauls, El pasado (2003), Mario Levrero, La novela luminosa (2005), Gustavo Ferreyra, La familia (2014) -otra novela de genealogías-, Mariana Enríquez, Nuestra parte de noche (2019). La lista es heterogénea, pero esos libros tienen en común la elección de la extensión como gesto de escritura afirmado y acompañado en general por una sofisticación expuesta de la construcción narrativa. En todo caso, el título humorístico que Juan José Saer eligió para su "novela larga", La grande (2005), muestra que, aunque minoritario o marginal, el fenómeno tiene una tradición reconocible de la que es posible burlarse.

10 En Becerra, se trata de ampliar y exacerbar las temáticas de sus últimas novelas, es decir, con palabras de Martín Kohan, las de ser "tratados sobre la relación del arte con la vida, del arte con la sociedad, del arte con el mercado, del arte consigo mismo" (2019), o bien, las de volver a representar y a poner en tensión el acto de narrar en sí mismo, según lo afirma Becerra (Guebel 2018). Por lo tanto, el protagonista de $\mathrm{El}$ espectáculo del tiempo, aunque no es escritor, funciona como un avatar de los protagonistas de muchas otras novelas, con un nombre, Juan Guerra, que lo sitúa en el borde de una autoficción guerrera (Guerra/Becerra) y que se prolonga con Andrés Guerrero, en su última novela, jFelicidades! (2019) (una novela que retoma las referencias a Cortázar, implícitas en El espectáculo del tiempo). Al mismo tiempo, la "gran" novela integra una historia de su escritura, con una línea de escenas y comentarios en forma de metalepsis sobre ese proceso, interrogado mientras se lleva a cabo.

11 En Guebel el gesto es mucho más calculado y más perceptible, en la medida en que $E l$ absoluto fue repetidamente anunciada por el escritor como una novela central, una novela que reuniría todo lo que el autor sabe, abriendo terrenos nuevos y en la que su "potencia creativa encuentra su momento cumbre", si tomamos al pie de la letra la definición que él maneja de la "novela total" en el encuentro que organizó para hablar de ese formato con Becerra y Alan Pauls (2018). Se sugiere así que, en alguna medida, las peripecias absurdas que constituyen las biografías de El absoluto, y en particular los recurrentes "momentos cumbre" que se representan allí (las anécdotas en que los antepasados "crean"), ponen en juego algo paródico pero serio. El lugar de El absoluto se 
confirma observando la bibliografía reciente de Guebel: una serie de otros textos la anuncian, se desprenden de ella o la prolongan (Sánchez 2014), desde prefiguraciones -Derrumbe (2007) - a libros que son digresiones y ampliaciones: Los padres de Sherezade (2008), Genios destrozados (2013), Los hijos del sol (Genios destrozados II) (2014). O textos que completan ciertos aspectos, como la relación con figuras referenciales, la infancia, los conflictos con el padre y su muerte -Mis escritores muertos (2009), El niño judío (2018)-. Guebel enfatiza, en entrevistas, la importancia de El absoluto, considerándola un "núcleo gravitatorio", un "núcleo duro" de su obra (Guebel en Andriaensen y Maier 2015).

Ampliando la perspectiva, antes de comentar las novelas, hay que subrayar que la biografía es a la vez una forma temporal y un dispositivo hermenéutico. Una forma temporal porque articula una serie de escenas marcadas por la sucesión (una vida está hecha de tiempo, o al menos su relato lo está) pero marcadas también por rememoración, evocación, combinación de planos, confrontación pasado/presente. La biografía es una forma temporal porque dramatiza la experiencia subjetiva de lo inmediato tanto como la presencia del pasado en el presente o el paso del presente al futuro. Guebel y Becerra llevan el fenómeno al paroxismo: uno exalta la profundidad y lo inagotable de cualquier narración del pasado, el otro expone el tiempo como una superficie lisa, plana, sin más allá significativo, puro suceder sin esencia. En estos casos, como lo indica Tiphaine Samoyault (2019 Web), la vida no es solo un proceso biológico sino un indicador de historicidad, ya que no se trata aquí de la vida biológica (engendramiento, reproducción, desaparición) sino de la vida en tanto vector de inserción en el tiempo (experiencia, memoria, transmisión, tradición).

13 Un dispositivo hermenéutico porque, como se lo ha indicado a menudo, la sucesión, inherente a su desarrollo, implica evolución, teleología, encadenamiento causal, origen, consecuencias, por lo que narrar una vida incluye siempre cierta hipótesis sobre las posibilidades de aprehender el sentido del sujeto y del mundo, o bien sobre las dificultades para hacerlo. Narrarla es una apuesta interpretativa que implica lo cognoscible de un humano, sean cuales fueren sus dispares resultados. Más allá, en su dinámica de mostración del devenir, la biografía postula cierta interacción entre vida y creación, entre experiencia y relato, entre vivencia y palabra $-\mathrm{y}$ por lo tanto cierta interpretación de todo eso-. Uno de los interrogantes más conocidos de la literatura moderna se perfila entonces, y es el de evaluar el entramado que acerca y separa las experiencias biográficas de la representación. Las vidas de escritores son, así, una historia paralela y significativa a la historia de las obras, que diluyen o reinventan los sentidos del pasado (muchos ejemplos, de Borges a Bolaño, permiten afirmarlo, y Guebel se inscribe fervorosamente en esta eventualidad). En otras, y siguiendo el valor dubitativo, autointerrogativo de la literatura moderna, se trata de repetir, una y otra vez, el choque contra el muro que separa lo vivido o lo recordado de lo narrable: es lo que sucede en Becerra.

Ambas ponen en el centro del intento de comprensión del arte y de la vida al padre, a la vez en el sentido biográfico y como una sinécdoque de una filiación más amplia del sujeto, de su historicidad, de su relación con la pertenencia y el pasado. Encontramos el mismo gesto en una abrumadora serie de libros recientes que interrogan las figuras paternas y maternas, con particular ahínco en el caso del padre y del duelo después de su muerte. En Argentina, muchísimas novelas en los últimos diez años recorren esta temática y esta posición interrogativa (Premat 2018b), sin ser un fenómeno de ninguna manera singular: en la literatura mundial, recuérdese el ejemplo, exacerbado y exitoso, 
de Karls Ove Knausgård, Mi lucha, 3500 páginas de una autobiografía que comienza y se justifica por la muerte del padre. Estamos ante un postrero avatar de la ejemplaridad, o sea ante la búsqueda de modelos en las vidas de los antepasados, lo que fue inherente a los relatos de ese tipo durante muchos siglos. Porque el resquebrajamiento de certezas no anula el anhelo de ejemplaridad, sino que ese anhelo se ha vuelto, desde fines del siglo XVIII, un componente paradójico que borra y actualiza, al mismo tiempo, el horizonte de los puntos de referencia.

Sea como fuere, tanto en el plano temporal como semántico, las narraciones actuales de una vida se confrontan con la misma inestabilidad que otros discursos contemporáneos: ausencia de futuro, omnipresencia de un presente vacío, interrogantes anhelantes a un pasado indiferenciado e imposibilidad de atribuirle un sentido a la experiencia, un sentido a la historia, un sentido a las variaciones imaginativas que, en la literatura, invierten y transforman vidas, tiempos, destinos.

\section{Becerra: una épica de lo nimio}

16 Para desarrollar las pistas arriba delineadas, un recorrido analítico más preciso por las dos novelas y los dos gestos biográficos. En el caso de Becerra, ante el caleidoscopio multiforme de su novela, opto por contrastar las dos primeras secuencias con lo que se expande luego en ella. Dos entradas la encabezan, situadas el mismo año (2002 es la fecha-título de ambas). La primera se refiere a un personaje ajeno al resto del libro, un longevo extraordinario, la segunda se refiere al padre del narrador, personaje central en lo que sigue.

"Murió José María Pardo. Tenía ciento doce años" es el íncipit de la novela. Enseguida, se nos cuenta que, cuando cumplió 110 años, al hombre le hicieron un acto, con un resultado inesperado:

El triunfo de la longevidad como milagro biológico que animaba la esperanza enfermiza de la vida eterna, en la que todas las personas razonables han caído alguna vez, se manifestó también como un fracaso espectacular de la memoria porque esa noche el discurso de Pardo revolvió una masa informe de fechas que desfilaron por las calles embarradas del recuerdo y que, en el apuro por resumir en pocos minutos una vida que se había prolongado de manera alarmante, arrastrando consigo un sinnúmero de experiencias pero también repeticiones que la reducían a una rutina de tedio, dejó flotando sobre los rumores obsecuentes de la sobremesa una idea inesperada de brevedad e intrascendencia. (Becerra 2015: 12)

18 Ante la expectativa social, ante la obsecuencia que hace de Pardo un "tótem cronológico, un objeto de emulación", se evidencian lo irrisorio de los deseos de longevidad y la enfermiza esperanza colectiva de duración (el duro deseo de durar del que hablaba Paul Eluard): Pardo no puede narrar su vida, apenas logra proponer una "masa informe de fechas" que transitan "por las calles embarradas del recuerdo". La duración es más que nada "alarmante", es una acumulación de experiencias repetidas y tediosas; la longevidad deseada desemboca en una idea, inesperada, de "brevedad e intrascendencia". El reverso del afán de duración es la falta de sentido y de relatos sobre ese inmenso pasado.

La secuencia, irónica en su yuxtaposición entre un deseo compartido y su resultado grotesco, anuncia el tono con el que se evocan ciertos imaginarios y angustias contemporáneos en lo que al tiempo se refiere. Más allá, las problemáticas temporales y 
melancólicas van a desplegarse, a lo largo de la serie de dispersas peripecias de la vida y de la memoria del narrador protagonista, Juan Guerra.

La "masa informe de fechas", el "sinnúmero de experiencias", las "repeticiones", la "longevidad" (o la duración) que desemboca en "intrascendencia", todo lo que obstaculiza un gran relato coherente en el ejemplo de Pardo, también resultan ser la imagen caricaturesca de lo que sigue: la novela está constituida por una serie importante de secuencias, ciento veinticinco, ante todo experiencias o recuerdos del narrador protagonista, situados en su mayoría entre los años 50 (alrededor de la figura del padre) y un pasado reciente (en los años 2000). Estas experiencias o recuerdos heterogéneos dibujan recorridos por pasados diferentes que se superponen, se repiten, se alejan, se prolongan, en un constante vaivén. Este desorden no parece tener ninguna forma de coherencia solapada como podía observárselas en el "Tablero de dirección" de Rayuela, novela que obviamente está en el horizonte de la de Becerra (en Rayuela se vislumbra un orden digamos argumental, aunque aparenta ser aleatorio).

21 Lo que unifica este milhojas temporal es el presente de la escritura o de la conciencia. La historia no es el pasado, la historia no está afuera, detrás, situada en una línea que progresivamente se acerca al momento de contemplación o de evocación, sino que la historia es lo que acompaña, por asociaciones y derivaciones múltiples, el ahora del sujeto. El pasado, en una visión caleidoscópica y panóptica, se nos presenta hoy como una multiplicidad simultánea, como un degradado Aleph borgeano. Y, efectivamente, varias secciones sobre el momento de la escritura o de la relectura del manuscrito de la novela (con fechas que van del 23 de noviembre de 2008 al 5 de diciembre de 2014) incluyen todo lo que precede en esa perspectiva de un ahora, que es el de la conciencia del sujeto que escribe y que es también el del voraz presente contemporáneo.

Por lo tanto, no son la lógica de un relato, y ni siquiera la reconstitución fragmentada e incierta del pasado gracias a la subjetividad de la memoria las que rigen la construcción de la novela, sino una especie de montaje, en el sentido cinematográfico: las series están "ajustadas" (como se ajustan los planos en el cine) con reenvíos, ecos, vinculaciones por continuidad metonímica. Se suceden a veces varias escenas disímiles engarzadas por el año en que sucedieron, se introducen recuerdos inferidos o sugeridos, por asociación, con la serie anterior (aunque el tema haya cambiado), se producen, entre diferentes secuencias, efectos de contrapunto o de paralelismo, tanto semántico como formal.

23 Volviendo a la primera secuencia sobre Pardo, se puede agregar que en ella también se introduce lo que funciona como el elemento coagulador del conjunto: una posición de atracción y fobia por la experiencia del tiempo, denominador común de los textos que siguen. Si las experiencias no constituyen un relato estructurado, si la vida no es narrable o no logra ser narrada, lo que sustituye estas formas ausentes es la obsesiva repetición y variación sobre modos de percibir, de representar y de pensar el decurso temporal. En ese sentido, encontramos en la novela un amplio repertorio de anécdotas, tematizaciones y figuras sobre el tiempo; sería tedioso enumerarlas, pero digamos que tienden a ser exhaustivas a pesar de la gran creatividad que la imaginación humana ha demostrado siempre al respecto.

Esta tematización y formalización del tiempo en tanto que espectáculo desemboca, como en la anécdota del cumpleaños de Pardo, en una estricta insignificancia -una vida no significa nada-, en un tedio, en una, de nuevo, "intrascendencia". 
El segundo texto que encabeza la novela introduce al padre, o más bien, metonímicamente, al padre a través de su casa, que se "deshace". En este caso se trata de algo que se parece más a una trama novelesca que empieza: el padre es, en alguna medida y en paralelo al narrador, el otro protagonista del libro. Así se introduce al personaje:

La casa de mi padre se deshacía en un barrio de Junín. Las fuerzas que sostenían su estructura se habían enfrentado durante años en la oscuridad del subsuelo, fracturándolo en líneas delgadas que avanzaron en zigzag, calaron los cimientos al método de un sismo privado y terminaron por separar el techo de losa en dos bloques unidos solamente por hilos de hierro, la prueba de que todo se inclina finalmente hacia la división. (14)

En la casa, como en el hombre, las potencias oscuras del tiempo han actuado, fracturando la construcción, erosionando los cimientos, separando los elementos del techo protector. Al padre le cortan la luz, el gas, el agua, el teléfono, la antena satelital: todas las conexiones con el presente. Enseguida nos enteramos que el padre está en decadencia, su comportamiento es irrisorio, sus proyectos patéticos. A su figura, punto de referencia y espejo que se interroga una y otra vez, se la introduce desde el después, desde el derrumbe, la debilidad, la incapacidad de enfrentar las fuerzas adversas.

Dos elementos de esta segunda secuencia se amplían en toda la novela. Por un lado, la importancia de la sucesión de generaciones, de la transmisión, del padre como recuerdo, como modelo y también como metáfora. El linaje (ascendente) y la filiación (descendente) son constantemente evocados en tanto que dispositivos de representación del tiempo: desde una bisabuela, todavía en vida cuando el narrador nació hasta bisnietos imaginarios que morirían hacia 2129, la situación temporal cristaliza interrogantes sobre el pasado, sobre el futuro, sobre una trascendencia vista en tanto que utopía deseada pero perdida.

En esta perspectiva, el padre, su pasado (infancia, juventud) y su inepcia, su mala fe, e incluso su carácter amenazador para el hijo, aparecen constantemente. En Juan Guerra se articula una autoficción signada por lo edípico (la guerra): la imagen de un hijo lidiando a la vez con la tentación del parricidio y la sombra de un filicidio -"Era un asunto de supervivencia: o él o yo" (166)-. La rivalidad va de par con la decepción, con la decadencia del padre, que es la otra cara o el otro nombre de la cronofobia y de sus efectos. La metáfora paterna es la de un cuestionamiento irresoluble sobre el valor del pasado, sobre modos de entender y de resolver las aporías temporales que vive el sujeto.

La filiación dispara acuciantes preguntas por el sentido entonces. No hay en la novela una sucesión lógica entre causas y efectos, no hay explicaciones ni resoluciones sobre lo anterior, sobre lo que ya no está y que contamina de inexistencia el presente. Porque la mayor parte de lo narrado está situada en lo cotidiano, del propio narrador, de un amigo cercano, de su padre; lo intrascendente es el terreno en el cual el flujo del tiempo se manifiesta con evidente sencillez. En una especie de apoteosis de lo banal se evidencia una forma de narración biográfica que deambula entre hiperrealismo y escepticismo. Becerra hace de la autobiografía un espectáculo, no solo del tiempo, sino de las diferentes facetas del sujeto; hace, también, de lo real un horizonte intermitente que rodea al yo sin explicarlo ni explicarse.

En esa perspectiva, él recorre las tres posibilidades que delimita Philippe Forest sobre el relato de la propia vida: apariencia de egografía primero (expresión directa de una 
subjetividad), la autoficción luego (percepción de sí mismo como personaje) y por fin heterografía, "escritura de una alteridad radical que es, una vez más, aquella a la que nos confronta lo imposible dentro de esa "experiencia soberana" en la que el sujeto se hace y se deshace a la vez" (2019 Web). La escritura de sí mismo como otro y del otro como yo, junto con la escritura de lo inmediato como lo ajeno y extraño -o, en palabras de Becerra: “... la autobiografía es justamente lo que no se puede hacer. Uno no puede contar su propia historia. Es imposible" (Becerra 2015b Web)-. El resultado, por lo tanto, decepciona: lo real es un incognoscible, el yo (que es también el yo creador) queda al descampado, hueco, extraño, fuera de alcance, fuera de toda filiación. Así puede entenderse otra afirmación de Forest, que parece aplicarse aquí, cuando escribe que la literatura no le da la espalda a lo real, sino que es una respuesta imposible a lo real (Forest 2007: 96).

31 En contrapunto, y con marcada ironía, la novela presenta una esfera digamos metafísica, cósmica, generalizante: pasamos así de la observación de una flor de metal por la que sale el agua durante la ducha cotidiana al "polvo cósmico que formó la Tierra" y a la destrucción de la actualidad (381). Estas aperturas hacia una distanciación máxima, la de los discursos filosóficos, la astrofísica, los grandes relatos temporales (Génesis, Apocalipsis), irrumpen a menudo. Por un lado, tenemos por ejemplo a un padre decadente, inoperante, irrisorio, por el otro el esbozo, en una breve segunda parte de la novela, de una Cosmogonía paródica que reduce el tiempo humano a una minúscula porción de una eternidad inabarcable. Esa parodia de un mito de origen empieza nada menos que por el Big Bang y se termina con una apocalipsis: "en el año 26.828.308.254, el Todo dejó de expandirse y en una microtrillonésima de lo que los Humanos alguna vez habían llamado segundo regresó a la Nada del principio" (199). La distancia máxima, que es también la del saber humano, la de la filosofía, la de la ciencia, la de la Historia, la de los grandes momentos del pensamiento, tampoco aclara ni precisa los enigmas abrumadores del tiempo. Demasiado cerca o demasiado lejos: la distancia nunca permite una comprensión operativa. La totalidad no existe y las peripecias, aunque proliferen, no constituyen un relato. Solo queda el desorden, la superposición, la sincronía que iguala todos los recuerdos en un presente tiránico frente a un tiempo devorador. La melancolía ni siquiera cobra los visos luctuosos de una queja metafísica. Todo es irrisorio. El espectáculo del tiempo propone una épica de lo nimio.

\section{Guebel: el ocaso de los genios}

En Guebel, más allá de su evidente relación con las vidas imaginarias (en la versión de Borges o de Bolaño), la dinámica de invención de historias está directamente empalmada con la "imaginación novelesca primordial" de la que habla Didier Anzieu, es decir la tendencia, ante todo infantil, de fabular sobre otros orígenes familiares, otros destinos, otras posibilidades en las vidas de padres, tíos, hermanos, hijos, todo lo cual viene a completar, compensar o contradecir lo decepcionante de la realidad y la frustración que implica renunciar a los idilios y a las idealizaciones de la primera infancia (1983: 217). Esta imaginación es una ampliación del concepto de "novela familiar" definido por Sigmund Freud, según la cual el niño resuelve los conflictos que le traen los cambios de edad, fabulando la existencia de otros padres o de otro padre (Robert 1972). 

sus antepasados?") instaura la filiación como primer nivel de fabulación y como causa explicativa de identidad artística. A la pregunta por los antepasados de Scriabin, El absoluto responde con una "vida imaginaria" del compositor ruso, retomando algunas anécdotas de su biografía y haciendo de sus creencias estéticas y metafísicas, del período y el lugar de su actividad, el marco de las biografías de los demás personajes. En particular, la concepción del arte y del artista que singularizaron a Scriabin definen la visión de la creación en toda la novela, hecha de la búsqueda de un absoluto -el título lo anuncia- y de una ambición mesiánica de incluir a la música en lo cósmico (el inacabado proyecto Mysterium, apoteosis de una ambición trascendente del arte, es el ápice de ese anhelo).

or de Scriabin se difunde entonces una digresiva novela familiar, gracias a la cual el músico no solo pasa a formar parte de la familia del niño-narrador de la sexta parte (o sea, que se introduce, se elige un origen ennoblecedor o heroico), sino que se multiplica y expande su figura en una serie de creadores que reproducen la megalomanía del compositor. El carácter común de todos ellos es el de ser definidos como "genios", en una repetida evaluación hiperbólica (cf. 484). La referencia a la genialidad es recurrente en los textos de Guebel, y en particular en la novela autobiográfica Derrumbe (2007), en la que el narrador tiene la certeza de ser un "genio", aunque fracasado, en la medida en que su obra, que busca responder a una "sed de absoluto" y que está compuesta de "libros maravillosos", no tuvo el reconocimiento esperado. La ironía y la afirmación de una ambición, aunque sea de segundo grado (absoluto, calidad de escritura, dimensión genial), marcan el tono y la temática de $E l$ absoluto. Y siguiendo con fantasías familiares: en alguna entrevista Guebel asocia su nombre judío, muy similar al de un criminal nazi célebre, Goebbels, con una serie de identificaciones heroicas: "En mi nombre y mis circunstancias está cifrada mi literatura. Me gustaría ser un Frankenstein entre Borges, Lamborghini, Libertella y Di Paola... con la elegancia de Henry James. Y sumémosle si queremos a Petronio, Cervantes, Benjamin Constant, Flaubert y Stendhal" (2015). Las fabulaciones biográficas de El absoluto están sugeridas en ese deseo de ser, de imaginarse ser, una combinatoria de grandes figuras de la historia de las letras.

a bien, a esta proliferación se le opone en la novela una ausencia: el niño narrador del final, que es después de todo el receptor y la justificación de lo que precede, pasa casi totalmente por alto a su padre -el padre y la familia paterna están apenas mencionados, y se los asocia con un origen bajo, bestial (492-493) - . Toda la filiación de genios termina en una mujer, la madre, antes de pasar al yo de la sexta parte, un niño que se inscribe a su vez en la serie, ya que concibe una máquina capaz de remontar el tiempo. Y como la madre no hace más que escribir la historia para transmitir esa memoria a su hijo, o sea que no se la incluye en la serie de genios, está claro de que se trata, no solo de afirmar el carácter masculino de la genialidad sino también de reemplazar al padre biográfico por una galería de figuras heroicas pero lejanas, lo que por otro lado es un tópico de la novela familiar. Todo lo que precede remite al mito de Edipo, al que se alude al final del libro (514).

falta de padre y el desequilibrio en la filiación, habituales puntos de partida de la fabulación familiar, se repiten en todas las vidas narradas. Ningún personaje es criado en una familia completa, estable, siempre falta alguno de los padres; las filiaciones son a veces electivas, a veces las madres mueren prematuramente. Esto es cierto desde la 
madre ausente de Frantisek (el tatarabuelo) hasta el problema del niño narrador final, que es la "ausencia" de la madre - "el misterio de la ausencia de mi madre" (490)—. La filiación irregular anuncia lo heroico -es un tópico mítico: nacimiento irregular y abandono posterior, en algunos casos acompañados por signos extraordinarios, como en vidas ejemplares o de santos (Rank 1981) - y tiene que ver con la creación: el absoluto que se busca es el contrapunto de una carencia originaria. En particular, la obvia consecuencia es que esa búsqueda está asociada con lo femenino, en términos sexuales (por ejemplo, Frantisek y sus orgías inspiradoras) o maternos (la máquina del tiempo final tiene como objetivo recuperar a la abuela del niño, fallecida recientemente; el invento reacciona ante un duelo imposible que recuerda el de En busca del tiempo perdido de Proust).

Además de la proliferación ennoblecedora de los orígenes y la repetición de filiaciones desequilibradas, un tercer rasgo asocia las historias narradas con la novela familiar, y es la mirada infantil dominante. Me refiero al narrador de la última parte, efectivamente un niño, pero también al resto. La infancia no es solo temática (un relato) sino que impregna la visión del mundo, las relaciones causa/efecto, la verosimilitud, las escalas de valores, las fuentes de información, sin dejar de lado un paradójico valor de seriedad -la seriedad del mundo visto por un niño-. O sea, no se trata de introducir una dinámica narrativa basada en el nonsense, como lo hacen o hicieron algunos escritores que circulan alrededor de las herencias vanguardistas (César Aira, Mario Bellatin, Pablo Katchadjian), sino que el despliegue imaginativo implica una reivindicación precisa: la de poder delirar la filiación, la de poder transformar la creación en una aventura inverosímil, la de liberar la escritura y la biografía de los imperativos del individualismo y de la impresión de haber llegado después y tarde, haciendo del disparate un estandarte. Inventar el pasado es una forma de utopía que se construye desde la infancia.

En todo caso, en El absoluto no hay aproximaciones a la historia familiar hechas de pesquisas, fotos halladas, documentos descubiertos, archivos consultados, versiones contrapuestas, según algunos tópicos del relato de filiación (Demanze). La geografía de la acción es imaginaria y el decir equivale al hacer, sin intervención de los imperativos de la realidad, lo que caracteriza una percepción infantil del mundo. Se trata de creer en lo narrado y no de justificar el saber o la verdad de lo que se narra. En esto el punto de vista afectivo y el saber de la voz narradora se asemejan a los de Cien años de soledad, libro al que se alude por otro lado de manera directa: en su túnel del tiempo el niño tiene, al final, una visión panorámica del pasado familiar (556-557) que se asemeja a la lectura del manuscrito de Melquíades en el desenlace de la novela colombiana, así como es semejante también el paralelismo entre genealogía y grandes acontecimientos históricos que entran y salen de la vida de los miembros de la familia.

De hecho, se desdibuja todo referente exterior a la imaginación textual, a pesar de los abundantes datos históricos. El borrado de una exterioridad del texto que determinaría y limitaría lo narrable es un gesto fundamental que parece alzar entonces la bandera de la libertad y de la potencia de la ficción: en Guebel se percibe una "exigencia de narrar", escribe Pauls, en tanto que gesto póstumo para intentar dialogar con los muertos (Andriaensen y Maier 2015). Para ello, se retoma un género vagamente asociado con lo historiográfico, la biografía, pero borrando cualquier veracidad o verosimilitud; aparecen grandes acontecimientos, como el exilio de Lenin o el viaje a Egipto de Bonaparte, pero lo que sucede antes y después carece de toda ambientación histórica 
estricta: es un antes indefinido. No hay contexto histórico, o la historia se reduce a una serie de ilustraciones dispares, como las que podrían figurar en alguna enciclopedia para niños, sin un metarrelato estructurante detrás.

Más allá del lugar que cada uno ocupa en la transmisión, no todos los antepasados están tratados con la misma exhaustividad. Sin embargo, algunas constantes señalan una continuidad, una repetición de generación en generación. Anoto algunas, que dialogan entre sí y que convocan concepciones reconocibles sobre las vidas de artistas. Primero, como lo señala la narradora al comienzo del libro, todos son "locos" o pasan por períodos de crisis, arrebatos creativos, depresiones y desequilibrios afectivos. Luego, todos son creadores originales, innovadores extraordinarios, que proponen lo nunca visto, lo revolucionario, lo radicalmente diferente $-\mathrm{y}$, significativamente, la innovación es, según los casos, artística o social, y supone una forma superior, un progreso en el saber o una utopía de organización colectiva de corte revolucionario: vanguardia política y vanguardia estética, como en la Rusia que sirve de marco a la novela, se superponen-. Por fin, otra característica recurrente, todos, a pesar de ser genios, fracasan de una manera $u$ otra: falta de reconocimiento social, incomprensión, obras destruidas, nombre olvidado, imposibilidad de llevar a cabo los grandiosos proyectos esbozados. En última instancia, se trata de suponer que se puede ser genial sin haber probado esa característica o sin que nadie se enterara de ello.

41 Sin ser monstruos, criminales y marginales, como lo son los protagonistas de los ejemplos más canónicos -Schwob, Borges, Wilcock, Bolaño (Premat 2010)-, la falta de reconocimiento de sus obras, la pérdida de ellas, la ignorancia por parte de las instancias de validación, hacen que estos locos sean "excéntricos", retomando la categoría generalizante que propone Cristian Crusat (2015). Inclusive en el caso de Scriabin: la apoteosis de "fanatismo scriabiniano" que después de su muerte se limitó a lo estrictamente musical "y se desentendió de la dimensión cosmogónica de su obra" (470): la fama como injusticia, el artista como incomprendido, el lugar del arte como un afuera inhóspito, son tópicos que se actualizan aquí. Y, última vuelta de tuerca, el niño de la última parte, deconstruye las certezas hasta allí enumeradas, termina sugiriendo la falsedad de lo narrado por su madre, la historiadora de la familia: "ellos no habían sido los genios que imaginó sino patéticas presencias conmovedoras, de figurantes de una ilusión distinta de la verdad que se había ido abriendo paso a medida que reconstruía sus biografías" (556).

Más allá, y retomando una tendencia que ya ha sido comentada en las vidas imaginarias (y en particular en las latinoamericanas, como las de Historia universal de la infamia de Borges o de Literatura nazi en América de Bolaño), estos relatos ponen en escena tensiones alrededor de la narración y de las posibilidades de contar una vida (Gefen $2012 \mathrm{Web}$ ). Como sus antecedentes, las vidas de Guebel suponen una representación problemática, una recuperación de concepciones encontradas sobre el lugar del artista, los objetivos del arte, su relación con el deseo, con el conocimiento, con la religión, con el poder, etc., o sea lo que se ha dado en llamar una dimensión metaliteraria. Muy específicamente, lo que vuelve una y otra vez en las trayectorias de estos genios es un interrogante sobre la vocación, sobre las condiciones de la creación, sobre los modelos y las transmisiones activas entonces, y al fin de cuentas sobre la validez del ideal romántico (y luego simbolista) que sirve de título a la novela, vale decir la búsqueda de un absoluto (Lacoue-Labarthe y Nancy 2012: 15-42). Estos interrogantes parecen responder al descreimiento, a la ironía generalizada, a la imposibilidad de una visión 
épica de nuestro contemporáneo, con un recurso a quimeras anacrónicas, esas que, precisamente, exaltaron, en algún momento de la historia, la excepcionalidad y la trascendencia del arte.

\section{Los hijos} relatos de vida (la biografía, lo memorialista, lo íntimo), que van más allá de lo que se denomina la "biografía", para inscribirse en un espacio más amplio, que podría denominarse "lo biográfico" (Broqua y Marche 2010: 5-6). Retoman y desbordan esos modelos, por un lado desde la exaltación irónica de la genialidad, por el otro, desde un panóptico que desarticula la obsesión ombliguista contemporánea. Lo biográfico, en ellas, enfatiza una dinámica de transmisión entre generaciones y entre períodos distintos - la constatación es ampliable a muchos otros autores-, o sea una presencia, una integración, una operatividad del pasado, de la memoria, de los muertos en el presente: por eso, dijimos, lo biográfico implica una forma temporal.

Una novela genealógica en Guebel (del pasado al presente en una historia familiar que alude lateralmente al ícono del género, Cien años de soledad), un relato de filiación en Becerra (del presente a indagaciones en el pasado en busca de respuestas a las encrucijadas actuales): con dos dinámicas opuestas, ambas interrogan el estatuto del sujeto y el lugar del escritor en contrapunto a sus antepasados. Lo que domina en Becerra es una imposible cronología hecha de proliferantes vaivenes, que despliegan el pasado en función de un presente, sin hallar una serie explicativa. En Guebel, se trata de una apoteosis de la novela familiar con biografías que acumulan bienes y personajes, pero que diluyen la transmisión en un patético fracaso final. Uno se sitúa en el exceso de la imposibilidad (incertidumbre, fragmentación, antiheroicidad), el otro en el exceso de la convención (vidas sucesivas y ejemplares, épica de antepasados, participación en la historia del saber humano) pero con resultados similares.

La secuencia edípica masculina, muy presente en ambos textos como vimos, se transforma a su vez en un esquema temporal o en todo caso en una manera de narrar y de situarse en una encrucijada de legados conflictivos y de identificaciones deseadas, trabadas o rechazadas con predecesores. Al legado y a la identificación los acompaña una tensión entre el quiebre y la prolongación, entre la idealización y la decepción, lo que sería una constante en la modernidad. Por un lado, se propugnan rupturas y ampliaciones de las fallas entre generaciones: Peter Sloterdijk afirma al respecto que la "Carta al padre" de Kafka es "un Hiroshima del intervalo genealógico" (2010: 60), o sea un vínculo entre padres e hijos que se vuelve hiato. Pero por el otro se repite la obsesión por crear puentes, tejer vínculos, pensar o curar lo que se ha roto, con una nostalgia y una negatividad características (Kaes 1993: 16), que en lo contemporáneo se acentúa en la dirección de querer rehabilitar lazos y despejar huellas relacionales. En esa tensión, si partimos de las posiciones de Becerra y Guebel, la imagen hoy sería la del escritor que recorre el espacio de una transmisión deseada pero perturbada, un escritor que también se enfrenta con la negatividad, intentando resucitar deseos que existieron y se expresaron en el momento del engendramiento del presente. Allí se encontraría una profundidad temporal para el sujeto y una forma de pertenencia a una comunidad: la puesta en escena de la transmisión es la representación de la cadena de la cual el sujeto procede (Kaes 1993: 4). En el interrogante al padre interviene la renuncia a la 
capacidad mesiánica o narcisista de ser único, de autoengendrarse. Hoy, inventarse un padre es inventarse un sentido y narrar su fracaso es narrar la muerte de los héroes, es decir situar, en alguna parte, aunque sea en la pérdida, un resto que se asemeja a un ideal heroico.

Porque en ambas novelas (pero estoy pensado en muchas otras de la abundante bibliografía a la que aludí en la introducción) hay un agujero en la transmisión, una impresión de desherencia, una obsesión por restablecer, reparar, reanudar con los hilos de un pasado traspapelado: por lo tanto, una melancolía. La ironía, la totalidad anhelada y frustrada, el fracaso sistemático, la erudición vana, las alusiones a un saber ineficaz, son rasgos de ese tipo: Guebel se inventa una historia anterior, con insolencia, pero reconociendo al final su vacío; Becerra intenta una ardua reconstrucción, que choca contra lo irrecuperable y que expande mediocridades del pasado simétricas a las del presente. La transmisión es por lo tanto ambivalente: vivificante y erotizada a veces, y otras, mortificante, negativa; la transmisión se vuelve una transmisión fallida, la de los deseos no realizados de los padres, de aquello que no sucedió, que no fue inscrito (Kaes 1993: 9-22). La constatación tiene que ver con la depresión, pero la perspectiva depresiva, en este caso como en muchos otros - por ejemplo en ciertos avatares de la vanguardia-, le da una potencialidad creadora a la negatividad (Grenier 2004).

Sea como fuere, la genealogía, la filiación, el esquema edípico, son los instrumentos para interrogar, poner en escena, actuar, la relación de los autores contemporáneos con la tradición. Escribir la transmisión es escribir una posibilidad de seguir creando, o sea que es escribir el futuro. En todo esto se perciben las fascinaciones actuales por el pasado, un pasado en el que se ocultarían utopías para el futuro, un pasado que, como el padre de Hamlet, ya no está pero vuelve, o sea que se trata de un pasado espectral, inasible, en el que se buscan respuestas. Por lo tanto, no es sorprendente que $\mathrm{El}$ espectáculo del tiempo y $\mathrm{El}$ absoluto (tanto como una zona importante de la producción literaria actual), estén escritas desde un anacronismo programático, desde una adhesión a esas "grandes novelas", a las ambiciones de la literatura del pasado, y desde un rechazo a las jerarquías impuestas por lo actual (Premat 2018a). Muchos aspectos de los dos libros permiten esta constatación, y uno de ellos es, justamente, la mirada, no solo tradicionalmente edípica, sino fuertemente masculina sobre la literatura, sobre la escritura y sobre la posición femenina como equivalente del objeto deseado y emblema de lo que se desea crear.

La heroicidad de la fantasía propuesta por Guebel o el inestable laberinto narrativo y temporal de Becerra dialogan entonces, en términos de contexto de producción (comienzos del siglo XXI en Argentina), con el exacto opuesto de lo que proponen: el fin de las grandes novelas, la pérdida del valor de la literatura, la incredulidad sobre la misión reveladora del discurso estético en el plano social o sobre la validez de la sofisticación narrativa como espacio de cuestionamiento. El virulento anacronismo del planteo, pero también los conflictos o fisuras que contiene, perfilan una "historia literaria no académica" (García Jurado 2010; Crusat 2015), una "ficción de historia literaria" (Jeannelle 2009), una historia inventada del arte, que reorganizaría las influencias, periodizaría de otra manera y restauraría el lugar de los supuestamente olvidados.

El abanico de temas tratados (filiación, memoria, encrucijadas de la creación, efectos de lo escrito) confirma entonces que las maneras de narrar una vida ponen en movimiento 
maneras de definir y de concebir la literatura en un momento dado, y en particular los procesos de autocontestación, puesta en duda, discusión de la literariedad que caracteriza a la literatura moderna (Jefferson 2012: 9-37). La vida cristaliza una concepción de la literatura, una historicidad de la idea de literatura (Gefen 2008 Web). Porque, más allá del cómo se narra una vida, cabe preguntarse sobre el qué (¿qué dicen las narraciones de una existencia hoy?) e incluso sobre el para qué (¿para qué se las narra hoy?, ¿cuál es su valor performativo?), abriendo un abanico de interrogantes sobre ese esquema narrativo. La biografía es una forma entonces pero también un telón de fondo que completa y justifica la obra (Jefferson 2012: 9-37). De una manera u otra, tiene un valor demostrativo que resuelve, narrativamente, el arduo problema de la explicación de lo inexplicable, vale decir de la vocación, de la creación.

Por otro lado, estas introspecciones en una historia familiar son significativas, también, de una evolución de la literatura argentina del siglo XXI, que fue agotando progresivamente los tópicos memorialistas sobre la dictadura (primero las incursiones en la historia nacional y en el relato de las víctimas, luego en el de los hijos) para abrir pesquisas en otras memorias, en otros pasados, que son más íntimos y que proliferan desde hace unos diez o quince años, según el esquema del "relato de filiación" que formalizó Dominique Viart (2019 Web). Desde este punto de vista, y retomando la asociación entre memoria de los padres/memoria literaria, podría decirse que Guebel y Becerra -y quizás varias generaciones de autores y autoras actuales- escriben una literatura de hijos o hijas, en un doble sentido. Por un lado, una literatura obsesionada por el pasado personal, por la figura del padre real o fantaseado, en tanto interrogante crucial para situarse en un presente desorientado. Pero, por otro lado, una literatura de los que llegaron después, los que solo pueden concebirse en tanto que prolongaciones, conflictivas o armoniosas, de las grandes novelas, de los grandes escritores, de lo agotado. Una literatura de escritores del post-, esbozando una forma inesperada de lo que se ha denominado la postmemoria: la literatura de un tiempo en el que la literatura ya sucedió (Premat 2020). Pareciera que, a pesar de la extensión y la sofisticación de sus "novelas totales", a pesar de sus largas trayectorias artísticas, Guebel y Becerra no terminan de alzarse al lugar de escritores referenciales, siguen siendo hijos, lo que sería un síntoma de época.

51 Confirmando la hipótesis, Guebel, para introducir el debate sobre la "novela total" con Becerra y Pauls -al que ya aludí-, parafraseó la frase de Adorno sobre la escritura después de Auschwitz, preguntándose, no si se puede seguir escribiendo poesía, sino si se pueden escribir novelas totales después de los grandes ejemplos del pasado (o sea, si se puede escribir después). La recuperación de ciertos aspectos de Cien años de soledad y de Rayuela, es decir la recuperación de aquellos libros que parecen ser los íconos más desgastados, menos actuales, de la literatura latinoamericana del siglo XX, es a ojos vista un síntoma al respecto, junto con, dijimos entonces, la ambición de una novela totalizadora que apunta a la idea fuerte de "obra" y a la reivindicación de una posición masculina ante la escritura.

52 Ahora bien, sería una lectura apresurada decir que Guebel reescribe genealogías como en Cien años de soledad y Becerra intenta reproducir aspectos de Rayuela en la organización aleatoria de los capítulos y en la representación de las posibilidades de escritura y de su proceso junto con la narración. Sin embargo, esas referencias, tan insólitas como anacrónicas en términos de contexto, sugieren a su vez una historicidad extraña que llevan a preguntarse sobre la relación entre lo biográfico y la novela hoy. 
Porque tiempo, sentido y experiencia es lo que se articula y se delira en la forma biográfica y por ende, lo biográfico y la novela tienden a confundirse. 0 , dicho de otra forma, si hay un modelo genérico convocado, discutido y puesto en tensión en las biografías contemporáneas, es el género novela en sí mismo. Las variantes biográficas o autobiográficas intentan darle cierta legitimidad a una creación literaria desvirtuada y al mismo tiempo interrogan, cimientan, el lugar de la novela futura.

\section{BIBLIOGRAFÍA}

Adriaensen, Brigitte y Gonzalo Maier, Todos los mundos posibles. Una geografía de Daniel Guebel, Rosario, Beatriz Viterbo, 2015. Ebook.

Amaro, Lorena, "De la "vida de artista" a la "fábula biográfica", autores quiméricos en las obras de Bolaño, Bisama, Guebel y Pron", en Literatura y Lingüística $N^{\circ} 36,2017$, Santiago de Chile, Universidad Católica Silva Henríquez, p. 149-175, Web. Consultado el 1 de abril de 2020.

Anzieu, Didier, Le corps de l'œuvre, París, Gallimard, 1981.

Avaro, Nora, Julia Musitano y Judith Podlube (comps.), Un arte vulnerable. La biografía como forma, Rosario, Nube negra, 2018.

Becerra, Juan José, El espectáculo del tiempo, Buenos Aires, Seix Barral, 2015a.

---, "El discurso de la pornografía está totalmente integrado al discurso familiar", entrevista con Patricio Zunini, 2015, Blog de Eterna Cadencia, Web. Constulado el 1 de abril de 2020.

---, "La literatura es una disciplina terrorista", entrevista de Luciano Lamberti, 2019, Blog de Eterna Cadencia, Web. Consultado el 1 de abril de 2020.

Bourdieu, Pierre, "L'illusion biographique", Raisons pratiques. Sur la théorie de l'action, París, Seuil, 1994, p. 81-90.

Broqua, Vincent y Guillaume Marche (eds.), L'épuisement du biographique, Newcastle upon Tyne, Cambridge Scholars Publishing, 2010.

Crusat, Cristian, Vidas de vidas. Una historia no académica de la biografía. Málaga, Páginas de Espuma, 2015.

Demanze, Laurent, "Récits de filiation”, en Encres orphelines. Pierre Bergougnioux, Gérard Macé, Pierre Michon, París, José Corti, 2018, Web. Consultado el 1 de abril de 2020.

Forest, Philippe, Le roman, le réel et autres essais. Allaphbed 3, Nantes, Editions Cécile Defaut, 2008.

---, “La novela y lo real", entrevista de Laurent Zimmermann, Cuadernos LIRICO no 20, 2019,Web. Consultado el 1 de abril de 2020.

García Jurado, Francisco, "La historicidad de las historias no académicas, encuentros complejos entre literaturas antiguas y modernas", Actas del XVII Simposio de la Sociedad Española de Literatura general y comparada, Barcelona, 2010, p. 61-71, Web. Consultado el 1 de abril de 2020.

Gefen, Alexandre, "La littérature : une biographie", Acta fabula volume 9, numéro 8, septiembre de 2008, Web. Consultado el 1 de abril de 2020. 
---, "Au pluriel du singulier: la fiction biographique", Biographies. Mode d'emploi, Critique $n^{\circ}$ 781-782, 2012, p. 565-575, Web. Consultado el 1 de abril de 2020.

Giordano, Alberto, El giro autobiográfico de la literatura argentina actual, Buenos Aires, Mansalva, 2008.

Grenier, Catherine, Dépression et subversion: les racines de l'avant-garde, París, Centre Pompidou, 2004.

Guebel, Daniel, Derrumbe, Buenos Aires, Mondadori, 2007.

---, “De amores y teología”, entrevista, Clarín, 26 de junio de 2015, Web. Consultado el 1 de abril de 2020 .

---, El absoluto, Buenos Aires, Mondadori, 2016.

Guebel, Daniel, “La novela total. Charla con Alan Pauls y Juan José Becerra en Campo de batalla”, video, 2018, Web. Consultado el 1 de abril de 2020.

Jeannelle, Jean-Louis (ed.), Fictions d'histoire littéraire, Rennes, Presses universitaires de Rennes, 2009.

Jefferson, Ann, Le défi biographique, París, PUF, 2012.

Kaës, René, "Le sujet de l'héritage”, Transmission de la vie psychique entre générations, París, Dunod, 1993, p. 1-58.

Kohan, Martín, “Arte y realidad”, blog Eterna Cadencia, 2019, Web. Consultado el 1 de abril de 2020.

Lacoue-Labarthe, Philippe, Jean-Luc Nancy, El absoluto literario. Teoría de la literatura del romanticismo alemán, Buenos Aires, Eterna Cadencia, 2012.

Premat, Julio, Monstruos, infames y criminales. Ficciones biográficas, de Schwob a la actualidad, Lecciones Doctorales $n^{\circ} 7$, Medellín, Universidad de Antioquia., julio-diciembre de 2010. Reeditado en Literatura y libertad. Reconquistando la cultura, recuperando la memoria, Medellín, Universidad de Antioquia, 2017, p. 155-180.

---, Non nova sed nove. Anacronismos, inactualidades, resistencias en la literatura contemporánea, Roma, Quodlibet, 2018a.

---, "Los pasos en las huellas, la novela de memoria en Argentina", Romanica Olomucensia 30/1, 2018b, p. 125-138.

---, "La utopía del pasado, modos de permanencia en la literatura contemporánea", Robin Lefere, Fernando Díaz Ruiz, y Lidia Morales Benito (eds.), Perspectivas sobre el futuro de la narrativa hispánica: ensayos y testimonios - Cuadernos de América sin nombre, Alicante, Universidad de Alicante, 2020, en prensa.

Rank, Otto, El mito del nacimiento del héroe, Buenos Aires, Paidós, 1981.

Robert, Marthe, Roman des origines et origines du roman, París, Grasset, 1972.

Samoyault, Tiphaine, "La vida. El concepto de vida en la teoría literaria", Cuadernos LIRICO oㅡ 20, 2019, Web. Consultado el 1 de abril de 2020.

Sánchez Idiart, Cecilia, "Lo autobiográfico en Daniel Guebel: modos de subjetivación, violencias íntimas y figuras de artista de Derrumbe a Genios destrozados", III Coloquio internacional [Escrituras del yo], CETYCLI, Rosario, 2014, Web. Consultado el 1 de abril de 2020. 
Sarlo, Beatriz, Tiempo pasado. Cultura de la memoria y giro subjetivo. Una discusión, Buenos Aires, Siglo XXI, 2007.

Sloterdijk, Peter, Après nous le déluge. Les Temps modernes comme expérience antigénéalogique, París, Payot, 2016.

Viart, Dominique, "El relato de filiación. Ética de la restitución contra deber de memoria en la literatura contemporánea”, Cuadernos LIRICO no 20, 2019, Web. Consultado el 1 de abril de 2020.

\section{RESÚMENES}

Para contestar la pregunta que abre este número de Cuadernos LIRICO sobre las estrategias formales de las narraciones de una vida, propongo leer dos novelas. Dos novelas recientes de escritores argentinos conocidos, dos novelas ambiciosas, que a su manera se pretenden totales: $E l$ espectáculo del tiempo de Juan José Becerra (2015) y El absoluto de Daniel Guebel (2016).

Parto de tres hipótesis: postular que la biografía es una forma temporal, es decir la representación de un imaginario temporal, en este caso de un presente dominante y de un pasado anhelado; que es una forma hermenéutica, en particular con interrogantes al padre para intentar, vanamente, atribuirle sentido a la existencia del sujeto; que sus variantes son una respuesta a la situación actual de la novela: la vida sería la última historia narrable, en un período de debilitamiento de lo novelesco.

Entre relato de filiación y novela genealógica, los dos libros desembocan en fracasos, desfases temporales, melancolía, incertidumbre. Estos serían los rasgos de una literatura del después, de una literatura escrita cuando la literatura ya está terminada.

Pour répondre à la question posée par ce numéro de Cuadernos LIRICO, celle des stratégies formelles des récits d'une vie, je propose d'analyser deux romans. Deux romans récents de deux écrivains argentins reconnus, deux romans ambitieux qui, à leur façon, visent une totalité: $E l$ espectáculo del tiempo de Juan José Becerra (2015) et El absoluto de Daniel Guebel (2016).

Je pars de trois hypothèses. La première considère que la biographie est une forme temporelle, c'est-à-dire qu'elle représente des imaginaires temporels, dans ce cas-ci, ceux d'un présent dominant et d'un passé désiré. La seconde suppose qu'elle est une forme herméneutique, en particulier grâce à des questionnements au père pour essayer, en vain, d'attribuer un sens à l'existence du sujet. La troisième associe les variantes de la biographie avec la situation actuelle du roman: elle serait la dernière histoire racontable, dans une période d'affaiblissement du romanesque.

Entre récit de filiation et roman généalogique, les deux livres débouchent sur des échecs, des décalages temporels, de la mélancolie, de l'incertitude. Ceux-là seraient les traits d'une littérature écrite alors que la littérature est déjà finie.

To answer the question posed by this issue of Cuadernos LIRICO, that of the formal strategies of life stories, I propose to analyze two novels. Two recent novels by two well-known Argentine writers, two ambitious novels that, in their own way, aim for totality: El espectáculo del tiempo by Juan José Becerra (2015) and El absoluto by Daniel Guebel (2016).

I start from three hypotheses. The first considers that biography is a temporal form, that is to say that it represents temporal imaginaries, in this case those of a dominant present and a desired past. The second supposes that it is a hermeneutic form, in particular through questioning the father to try, in vain, to attribute a meaning to the subject's existence. The third associates the variants of the biography with the current situation of the novel: it would be the last story that can be told, in a period of weakening of the novel. 
Between the narrative of filiation and the genealogical novel, the two books lead to failures, times lags, melancholy, uncertainty. These would be the features of a literature written when literature is already finished.

\section{ÍNDICE}

Palabras claves: Novela contemporánea, novela argentina, historia, biografía, anacronismo.

Keywords: Contemporary novel, Argentine novel, history, biography, anachronism.

Mots-clés: Roman contemporain, roman argentin, histoire, biographie, anachronisme

\section{AUTOR}

\section{JULIO PREMAT}

Université Paris 8 - Institut Universitaire de France

ju.premat@wanadoo.fr 